\title{
Exploring the effects of a family admissions program for adolescents with Anorexia Nervosa
}

\author{
Keren Fink ${ }^{1 *}$, Paul Rhodes ${ }^{1}$, Stephen Touyz ${ }^{1}$, Andrew Wallis ${ }^{2}$, Jane Miskovic ${ }^{2}$, Sloane Madden², Michael Kohn ${ }^{2}$ \\ From 2015 ANZAED Conference: Riding the Waves to Recovery \\ Surfers Paradise, Australia. 21-22 August 2015
}

The present study aimed to qualitatively investigate patient experience and treatment efficacy of the Family Admissions Program (FAP) - a pilot treatment program being run at the Children's Hospital at Westmead for adolescents with Anorexia Nervosa (AN). Based on Maudsley Family Based Treatment (MFBT), the FAP involves an adolescent and his/her family undergoing a two-week family-based hospital admission at the outset of treatment. The program aims to increase intensity and support to a level needed by families at risk of responding negatively to traditional MFBT.

Narrative Inquiry and Interpretative Phenomenological Analysis (IPA) were used to analyse data obtained from participant interviews, exploring both the prospective expectations and retrospective experiences of families and clinicians participating in the program. Results from both of the qualitative analyses indicate that in cases where the family unit has been particularly fractured as a result of AN, the FAP offers an opportunity for relational strengthening and reunification, particularly within the parental subsystem. Combined with the program's intensive support, contained transition from hospital to home, and proximity to necessary hospital services, this serves to provide struggling families and parents with a more skilled and consolidated foundation for traditional outpatient MFBT.

\section{Authors' details}

${ }^{1}$ University of Sydney, Sydney, Australia. ${ }^{2}$ Children's Hospital at Westmead, Sydney, Australia.

Published: 23 November 2015
doi:10.1186/2050-2974-3-S1-048

Cite this article as: Fink et al:: Exploring the effects of a family

admissions program for adolescents with Anorexia Nervosa. Journal of Eating Disorders 2015 3(Suppl 1):O48.

* Correspondence: kfin8268@uni.sydney.edu.au

'University of Sydney, Sydney, Australia

Full list of author information is available at the end of the article

Submit your next manuscript to BioMed Central and take full advantage of:

- Convenient online submission

- Thorough peer review

- No space constraints or color figure charges

- Immediate publication on acceptance

- Inclusion in PubMed, CAS, Scopus and Google Scholar

- Research which is freely available for redistribution
C Biomed Central 